\title{
AS CARACTERÍSTICAS DA GESTÃO DE TESOURARIA NAS ORGANIZAÇÕES DA REGIÃO CARBONÍFERA DE SANTA CATARINA
}

\author{
Cleyton de Oliveira Ritta \\ Cristina Rui da Silva \\ Andréia Citadin \\ cleytonritta@gmail.com \\ cristinadasilva@hotmail.com \\ aci@udesc.net
}

Fundação Universidade Regional de Blumenau - FURB

\begin{abstract}
Resumo
O objetivo geral da pesquisa consiste em investigar as características da gestão de tesouraria nas empresas que compõem a Associação dos Municípios da Região Carbonífera - AMREC, de Santa Catarina. Para alcançar tal objetivo, realizou-se uma pesquisa descritiva de caráter qualitativo e quantitativo por meio de questionário do tipo fechado, aplicado em192 empresas por acessibilidade. Os resultados apontaram que a maioria das empresas: a) é de natureza jurídica Ltda.; b) atua no comércio e prestação de serviços; c) é de micro e pequeno porte; d) possui práticas adequadas de gestão de tesouraria de curto prazo; e) tem poucas aplicações e empréstimos no mercado financeiro; f) realiza financiamentos para veículos, máquinas e equipamentos e g) capta recursos em bancos múltiplos/comerciais e bancos de desenvolvimento. Conclui-se que as organizações pesquisadas possuem uma situação organizacional de gestão adequada de tesouraria de curto prazo; entretanto, nas atividades de tesouraria de longo prazo, muitas empresas não realizam controles de orçado/realizado e de planejamento financeiro com políticas de investimentos, empréstimos e financiamentos. Essa situação representa importante fragilidade de gestão financeira, pois evidencia que algumas entidades não possuem visão de longo prazo.
\end{abstract}

Palavras-chave: Administração Financeira. Gestão de Tesouraria. Associação dos Municípios da Região Carbonífera - AMREC.

\begin{abstract}
The main objective of this research is to investigate the characteristics of the treasury management in companies that constitute the Association of Municipalities of the Coal Region - AMCR - of the state of Santa Catarina.To reach this goal, a descriptive qualitative and quantitative research was conducted, through a closed questionnaire answered by 192 companies by accessibility. The results showed that most companies: a) are of a legal nature Inc.; b) act in the area of trade and services; c) are micro and small; d) have appropriate treasury management practices of short-term; e) have few investments and loans in the financial market; f) carries out financing for vehicles, machinery and equipment; and g) capture resources in multiple/commercial banks and development banks. It can be concludedthat the surveyed companies have adequate organizational treasury management situation of short-term; however, many companies, regarding the long-term treasury activities,do not conduct budgeted/performed controls with financial planning and investment policies, loans and financing.This situation represents an important weakness of financial management, highlighting that some organizations do not have long-term view.
\end{abstract}

R. Eletr. do Alto Vale do Itajaí - REAVI, v. 5, n. 8, p. 01-13, dez., 2016

ISSN: 2316-4190, DOI: 10.5965/2316419005082016001 
Keywords: Financial Administration; Treasury Management; Association of Municipalities of the Coal Region - AMCR.

\section{Introdução}

A gestão de tesouraria é o conjunto de atividades que administra as entradas e saídas de recursos nas organizações. Por isso, é preciso planejamento das ações gerenciais relacionadas aos investimentos e captações de recursos de curto, médio e longo prazo. A administração financeira tem por objetivo controlar a aplicação e a captação de recursos, a concessão de crédito para clientes e o planejamento empresarial, no intuito de possibilitar a continuidade dos negócios e maximização do desempenho organizacional (HOJI, 2000; GITMAN, 2010; GROPPELLI; NIKBAKHT, 2010).

Silva (2007) menciona que a administração financeira compreende três dimensões: a) a primeira é o controle das operações de curto prazo da organização no que tange às funções de tesouraria; b) a segunda refere-se às operações de longo prazo em relação a clientes, fornecedores e instituições financeiras e c) a terceira relaciona-se às atividades estratégicas com ênfase nas decisões de investimento, financiamento, distribuição de resultados e planejamento financeiro.

A administração financeira objetiva manter uma situação de liquidez nas operações e seu papel está atrelado ao tamanho das companhias e complexidade das atividades. Nas empresas de grande e médio porte, geralmente, há uma área específica responsável pelas transações. Por outro lado, nas micro e pequenas empresas as atividades financeiras são acumuladas pelos proprietários em grande parte. Segundo Silva (2007), nas pequenas empresas, muitas vezes, não há um setor específico, uma vez que o gerenciamento financeiro é uma das principais funções do proprietário. Portanto, na medida em que a empresa cresce, torna-se necessário um setor específico sob o comando de um profissional independente com conhecimento na área de finanças.

O papel do administrador financeiro consiste em assegurar que os objetivos organizacionais sejam atingidos, como por exemplo: maximizar o lucro, minimizar os custos das operações e criar valor para os proprietários. Segundo Ross, Westerfield e Jordan (2002), o administrador financeiro deve se preocupar com questões de estrutura de capital, administração do capital de giro e gestão de tesouraria.

Dentre as áreas de atuação do administrador financeiro destaca-se a gestão de tesouraria, que é a área responsável pela manutenção de liquidez das organizações. Sua principal função é gerir investimentos, captar recursos e planejar o fluxo de caixa.

Diante deste contexto, surge a seguinte pergunta de pesquisa: Quais são as características da gestão de tesouraria nas organizações da região da AMREC, de Santa Catarina? O objetivo geral da pesquisa é investigar as características da gestão de tesouraria nas organizações da região da AMREC,de Santa Catarina. Para atingir o objetivo geral, foram estipulados os seguintes objetivos específicos: (i) descrever as características das organizações; (ii) verificar aspectos administrativos de tesouraria; (iii) conhecer as modalidades de aplicações e de captações de recursos e (iv) verificar as fontesde captação de recursos.

A justificativa para o estudo tem como argumento o aumento da concorrência empresarial na região carbonífera, uma vez que se percebe o surgimento de novas empresas de pequeno, médio e grande. Portanto, as práticas de gestão de tesouraria dessas organizações devem ser investigadas,pois é fator importante para a continuidade dos negócios.

Neves e Pessoa (2006), SEBRAE-SP (2008) e Santos, Ferreira e Faria (2009) observam que os principais motivos que causam o fechamento de empresas é a falta de informações 
financeiras e de planejamento para o gerenciamento das atividades organizacionais. Sendo assim, o levantamento das características de gestão de tesouraria nas organizações da região contribui para a compreensão de seu funcionamento, a fim de identificar potencialidades e fragilidades na situação financeira dasentidades.

O artigo está estruturado em cinco seções, incluindo esta introdução. A segunda seção trata da fundamentação teórica que abrange aspectos sobre gestão de tesouraria e mercado financeiro. Na terceira seção descreve-se a metodologia da pesquisa. Na quarta apresentam-se os resultados da pesquisa. Por fim, a quinta seção é dedicada às considerações finais.

\section{Revisão Bibliográfica}

\subsection{Gestão de tesouraria}

A administração financeira tem como foco o aumento da riqueza dos investimentos realizados pelos proprietários nas organizações. Segundo Lemes Junior, Rigo, Cherobim (2010, p. 5), o objetivo da administração financeira é "'maximizar a riqueza da empresa".As decisões financeiras devem aumentar o valor de mercado das organizações e otimizar a aplicação do capital investimento.

Hoji (2000) observa que, do ponto de vista dos proprietários, uma empresa pode ser vista como um sistema que gera lucro e aumenta os recursos nela investidos. Por meio de seus gestores e colaboradores, a empresa interage com outros agentes do ambiente econômico e gera resultados financeiros que remuneram os proprietários pelo investimento realizado.

Dentre as responsabilidades da administração financeira destaca-se a gestão de tesouraria,que é um conjunto de atividades que dá suporte para a tomada de decisão, pois é responsável pela entrada e saída de recursos, além de estabelecer políticas gerenciais de curto, médio e longo prazo.

A gestão de tesouraria administra a movimentação dos recursos financeiros, que são fundamentais para manutenção da liquidez nas operações diárias.De acordo com Santos, Ferreira e Faria (2009, p. 76), a gestão de caixa deve existir pelas seguintes razões:

- obter descontos dos fornecedores, tendo em vista que o custo de não utilizá-los é alto;

- manter a classificação de crédito, por meio da liquidez corrente e sua liquidez seca alinhadas com as de outras empresas de seu setor;

- aproveitar oportunidades de negócios favoráveis, como promoções especiais dos fornecedores ou a chance de adquirir outra empresa.

- enfrentar emergências como greves, incêndios ou campanhas de marketing dos concorrentes e também para suportar quedas sazonais ou cíclicas no nível de atividade.

A tesouraria tem como principal instrumento gerencial o Fluxo de Caixa, que é utilizado para controle e planejamento das movimentações financeiras ocorridas num determinado horizonte de tempo. Esse instrumento pode ser estruturado de modo diário, semanal, mensal e anual, com valores acumulados ou não. Para Gitman (2010), o fluxo de caixa é a preocupação básica do administrador financeirona gestão das finanças do cotidiano, em questões de planejamento financeiro e na tomada de decisões estratégicas voltadas para a criação de valor para os proprietários.

Para Santos (2001, p. 57), a função do Fluxo de Caixa é "(1) planejar a contratação de empréstimos e financiamentos; (2) maximizar o rendimento das aplicações das sobras de caixa; (3) avaliar o impacto financeiro de variações de custos; e (4) avaliar o impacto financeiro de aumento de vendas".

Lemes Júnior, Rigo e Cherobim (2010) observam que as políticas de investimento, de vendas, de crédito, de compras e de estoques impactam diretamente no caixa das 
organizações. Logo, o administrador financeiro deve participar das definições das políticas gerenciais, orientando-as, para que não ofereçam problemas de liquidez.

Zdanowicz (2004, p. 29) detalha outras funções do administrador financeiro:

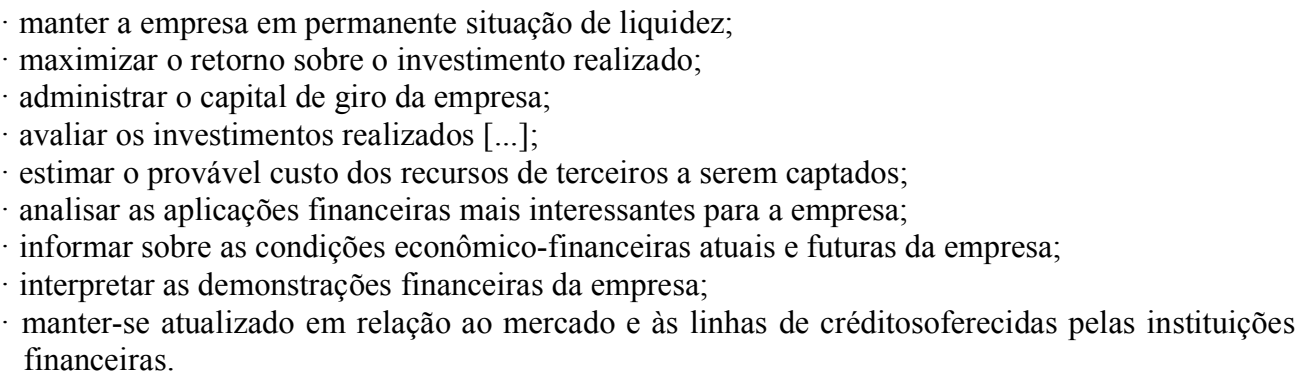

$\mathrm{O}$ administrador financeiro tem o papel de manter o Fluxo de Caixa com saldo positivo. O saldo de caixa positivo representa "valores em moeda, mantidos na tesouraria da empresa ou depositados em conta correntes bancárias, de liquidez imediata e, em sua maior parte, livres para serem usados a qualquer momento" (LEMES JÚNIOR;RIGO; CHEROBIM, 2010, p. 375).

O saldo de caixa evidencia a situação financeira da empresa. Por isso, uma gestão de tesouraria adequada concilia o planejamento de caixa com as áreas administrativa, comercial e de produção no intuito de garantir a continuidade dos negócios, sem falta de recursos.Logo, o sucesso de uma empresa está vinculado ao controle e planejamento do fluxo de caixa, uma vez que representa um instrumento importante para a administração das organizações.

\subsection{Mercado financeiro}

A função do mercado financeiro é intermediar recursos financeiros de grupos que investem capitais (poupadores) para acumular rentabilidades ao longo do tempo e grupos que captam recursos (tomadores) para suprir necessidades do dia a dia ou ampliar a capacidade de investimento. Para Lima, Lima e Pimentel (2012, p.3), "no primeiro grupo, surge a questão de como aplicar os recursos em excesso, enquanto o segundo grupo preocupa-se em como obter os recursos necessários à viabilização de seus projetos de investimento".

O mercado financeiro é estruturado do seguinte modo: a) mercado monetário operações de curto e médio prazo que disponibiliza recursos para manutenção de liquidez das pessoas ou empresas; b) mercado de crédito - operações de médio e longo prazo, geralmente vinculadas acapital de giro e financiamento das organizações; c) mercado de capitais operações que envolvem a comercialização de ações de empresas nas bolsas de valores; e d) mercado cambial - envolve operações com moeda internacional (ASSAF NETO, 2007).

As instituições financeiras podem realizar operações ativas e passivas. As operações ativas são aquelas em que a instituição empresta recursos aos seus clientes (empréstimos/financiamentos). Nas operações passivas,a instituição recebe recursos de seus clientes tendo que devolvê-los no futuro (investimentos).

No mercado financeiro existem diversas modalidades de investimentos. O Quadro 1 apresenta as principais modalidades.

Quadro 1 - Investimentos

\begin{tabular}{|c|l|}
\hline \multicolumn{1}{|c|}{ Investimentos } & \multicolumn{1}{|c|}{ Descrição } \\
\hline \multirow{3}{*}{ Caderneta de Poupança } & $\begin{array}{l}\text { A caderneta de poupança é essencialmente uma alternativa de aplicação } \\
\text { financeira bastante conservadora [...] e de baixa remuneração, } \\
\text { comparativamente a outros tipos de ativos no mercado. Tem como } \\
\text { vantagem ao aplicador, ainda, a isenção do Imposto de Renda (ASSAF }\end{array}$ \\
\hline
\end{tabular}




\begin{tabular}{|l|l|}
\hline & NETO, 2007, p. 82). \\
\hline Títulos de Renda Fixa & $\begin{array}{l}\text { Os títulos de renda fixa são todosos títulos, públicos ou privados, com } \\
\text { rendimentos finais e periódicos, estabelecidos por regras pré-determinadas, } \\
\text { sendo o prazo mínimo permitido de 30 dias (FARIAS, 2002, p. 208). }\end{array}$ \\
\hline Títulos de Renda Variável & $\begin{array}{l}\text { As ações são títulos que representam a participação dos sócios (motivo } \\
\text { pelo qual estes também são chamados de acionistas) no capital de uma } \\
\text { empresa constituída sob a forma jurídica de Sociedade Anônima-S.A. } \\
\text { (WERNKE, 2008, p. 83). }\end{array}$ \\
\hline Fundos de Investimentos & $\begin{array}{l}\text { Os fundos, por se apresentarem como forma coletiva de aplicação de } \\
\text { recursos, trazem vantagens, sobretudo ao pequeno investidor com baixo } \\
\text { volume individual de capital disponível para aplicação financeira (ASSAF } \\
\text { NETO, 2007, p. 267). }\end{array}$ \\
\hline
\end{tabular}

Fonte: Elaborado pelos autores

Cabe ao investidor a escolha entre as diversas modalidades de acordo com sua expectativa de rentabilidade, custo e risco.

Em relação às modalidades de empréstimos/financiamentos, o Quadro 2 apresenta as principais opções.

Quadro 2 - Empréstimos e financiamentos

\begin{tabular}{|c|c|}
\hline Empréstimos/Financiamentos & Descrição \\
\hline Cheque especial & $\begin{array}{l}\text { Cheque é especial quando concede ao seu titular um limite de crédito para } \\
\text { saque, utilizável quando não apresentar fundos em sua conta. O cheque } \\
\text { especial é concedido mediante a assinatura de um contrato de abertura de } \\
\text { crédito, em que são definidos o limite de crédito, prazo de contrato, taxa } \\
\text { de juros cobrada sobre o saldo devedor, etc. (ASSAF NETO, 2007, p. 74). }\end{array}$ \\
\hline Conta Garantida & $\begin{array}{l}\text { Conta garantida equivale à abertura de uma conta com um limite de } \\
\text { crédito garantido pela instituição bancária. O mutuário da operação saca } \\
\text { fundos até o limite contratado para saldar suas necessidades mais } \\
\text { imediatas de caixa. As contas garantidas são movimentadas geralmente } \\
\text { mediante cheques, podendo ocorrer depósitos para cobrir (ou reduzir) o } \\
\text { saldo devedor existente (ASSAF NETO, 2007, p.71). }\end{array}$ \\
\hline Desconto de Título & $\begin{array}{l}\text { Se o credor de uma duplicata, cujo vencimento se dará em alguma data } \\
\text { futura, necessitar de dinheiro, poderá negociá-la junto a um banco, isto é, } \\
\text { receber à vista o valor de seu crédito mediante o pagamento de alguma } \\
\text { compensação financeira. O valor liberado ao tomador é inferior ao valor } \\
\text { nominal (valor de resgate) dos títulos, em razão da cobrança antecipada } \\
\text { dos encargos financeiros, caracterizando assim a operação de desconto } \\
\text { bancário(ASSAF NETO, 2007, p.70). }\end{array}$ \\
\hline Capital de giro & $\begin{array}{l}\text { As operações de capital de giro visam suprir as necessidades de recursos } \\
\text { do ativo circulante (capital de giro) das empresas. As operações são } \\
\text { realizadas geralmente dentro de um prazo de resgate de } 6 \text { a } 24 \text { meses e os } \\
\text { pagamentos podem ser realizados de uma única vez (ao final do prazo) ou } \\
\text { em prestações periódicas (mensais, trimestrais, etc.). As garantias exigidas } \\
\text { são normalmente duplicatas, avais ou hipoteca de ativos reais (ASSAF } \\
\text { NETO, 2007, p. 76). }\end{array}$ \\
\hline $\begin{array}{l}\text { Crédito Direto ao } \\
\text { Consumidor }\end{array}$ & $\begin{array}{l}\text { O CDC é uma operação tipicamente destinada a financiar aquisições de } \\
\text { bens e serviços por consumidores ou usuários finais. A concessão do } \\
\text { crédito é efetuada por uma sociedade financeira e a garantia usual da } \\
\text { operação é a alienação fiduciária do bem objeto do financiamento } \\
\text { (ASSAF NETO, 2007, p. 72). }\end{array}$ \\
\hline $\begin{array}{l}\text { Arrendamento Mercantil } \\
\text { (leasing) }\end{array}$ & $\begin{array}{l}\text { Essa modalidade é praticada mediante a celebração de um contrato de } \\
\text { arrendamento (aluguel) efetuado entre um cliente (arrendatário) e uma } \\
\text { sociedade de arrendamento mercantil (arrendadora), visando à utilização, } \\
\text { por parte do primeiro, de certo bem durante um prazo determinado, cujo } \\
\text { pagamento é efetuado em forma de aluguel (arrendamento) (ASSAF } \\
\text { NETO, 2007, p.77). }\end{array}$ \\
\hline
\end{tabular}

Fonte: Elaborado pelos autores. 
Cada modalidade de captação atende às expectativas do tomador de recursos de acordo com o custo de captação, prazo, tarifa e garantia a serem oferecidas.

O mercado financeiro é composto por instituições que intermediam a negociação de recursos entre os investidores e tomadores. Segundo Pacheco (2005, p. 14), o mercado "é um conjunto de instituições que atuam no processo de conciliar interesses de agentes deficitários e superavitários e de converter poupança em investimento".

Os principais agentes do mercado financeiro brasileiro são: bancos de investimento, cooperativas de crédito, sociedade de arrendamento mercantil, sociedades de crédito, bancos de desenvolvimento, bancos comerciais, bancos múltiplos e empresas de factoring (ASSAF NETO, 2007). O Quadro 3 apresenta as características desses agentes.

Quadro 3 - Instituições do mercado financeiro
\begin{tabular}{|l|l|}
\hline \multicolumn{1}{|c|}{ Instituições } & \multicolumn{1}{c|}{ Características } \\
\hline Bancos de Investimentos & $\begin{array}{l}\text { Fornecem recursos de longo prazo para necessidades de capital de giro e de } \\
\text { ativos de natureza permanente. }\end{array}$ \\
\hline $\begin{array}{l}\text { Bancos } \\
\text { Múltiplos/Comerciais }\end{array}$ & $\begin{array}{l}\text { Atendem a investidores e tomadores de recursos. Prestam serviços de cobranças, } \\
\text { seguros, corretagens, transferências de recursos, entre outros. }\end{array}$ \\
\hline $\begin{array}{l}\text { Bancos de } \\
\text { Desenvolvimento }\end{array}$ & $\begin{array}{l}\text { Concedem recursos de longo prazo visando ao desenvolvimento econômico e } \\
\text { social do país. }\end{array}$ \\
\hline Cooperativas de Crédito & $\begin{array}{l}\text { Realizam operações de aplicação e captação de recursos somente para } \\
\text { associados. }\end{array}$ \\
\hline Empresas de Factoring & $\begin{array}{l}\text { Compram créditos de empresas resultantes de vendas ou prestação de serviço e } \\
\text { prestam serviços de assessoria financeira. }\end{array}$ \\
\hline $\begin{array}{l}\text { Sociedades de } \\
\text { Arrendamento Mercantil }\end{array}$ & Efetuam operações de arrendamento mercantil (Leasing) de bens e serviços. \\
\hline $\begin{array}{l}\text { Sociedades de Crédito e } \\
\text { Financiamento }\end{array}$ & $\begin{array}{l}\text { Oferecem financiamento de bens duráveis por meio de Crédito Direto ao } \\
\text { Consumidor (CDC). }\end{array}$ \\
\hline
\end{tabular}

Fonte: Assaf Neto (2007); Silva (2008); Wernke (2008)

As instituições financeiras têm o papel de oferecer alternativas de aplicação e captação de recursos para pessoas físicas e jurídicas. Desse modo, intermediam o fluxo de recursos entre poupadores e tomadores.

\section{Metodologia da Pesquisa}

\subsection{Enquadramentometodológico}

A pesquisa caracteriza-se como descritiva de caráter predominantemente qualitativo com aplicação de questionário do tipo fechado. Quanto aos objetivos da pesquisa, o trabalho configura-se como descritivo, pois apresenta as características da gestão de tesouraria das empresas da região da AMREC. Segundo Martins Jr. (2008, p. 83), "a pesquisa descritiva visa descobrir e observar fenômenos existentes, situações presentes e eventos, procurando descrevê-los, classificá-los, compará-los, interpretá-los".

Em relação à abordagem do problema, a pesquisa é qualitativa e quantitativa, uma vez que busca compreendere mensurar dados referentes às características da gestão de tesouraria das empresas investigadas. Segundo Martins Jr. (2008, p. 132), a pesquisa qualitativa "é a descrição dos dados obtidos através de instrumentos de coleta dos dados, tais como: entrevistas, observações, descrição e relatos. Consiste em buscar a compreensão particular daquilo que se está investigando". A pesquisa quantitativa, por sua vez, "é a quantificação dos resultados provenientes da coleta dos dados sob a forma de símbolos matemáticos e/ou estatísticos. Para isso, são necessários dois procedimentos: a tabulação dos dados e sua representação sob a forma de tabelas ou gráficos”. (MARTINS JR. 2008, p. 128). 
A natureza da pesquisa é do tipo levantamento ou survey, pois se investiga certa quantidade de empresas para compreender aspectos de gestão de tesouraria. Segundo Pinheiro (2010, p. 23), o levantamento "ocorre quando a pesquisa envolve a interrogação direta das pessoas cujo comportamento se deseja conhecer".

Quanto aos procedimentos de coleta, a pesquisa utilizou questionário do tipo fechado para coleta de dados nas empresas da AMREC. Segundo Richardson (1999, p. 189), "os questionários cumprem pelo menos duas funções: descrever as características e medir determinadas variáveis de um grupo social. A informação obtida por meio de questionário permite observar as características de um indivíduo ou grupo".

\subsection{Caracterização do objeto de pesquisa}

A Associação dos Municípios da Região Carbonífera (AMREC) foi fundada em 25 de abril de 1983, inicialmente por 7 (sete) cidades da região sul de Santa Catarina: Criciúma (sede), Içara, Lauro Müller, Morro da Fumaça, Nova Veneza, Siderópolise Urussanga. Posteriormente, os municípios de Forquilhinha, Cocal do Sul, Treviso, Orleans e Balneário Rincão integraram a associação, totalizando 12 municípios (AMREC, 2012).

AAMREC é o maior pólo carbonífero do país e abastece o maior complexo termoelétrico da América Latina, denominada de usina Termoelétrica Jorge Lacerda. Além do segmento carbonífero, a economia da região destaca-se em outros segmentos, tais como: a) cerâmico, com o maior pólo concentrado de grandes indústrias cerâmicas do país; b) metalmecânico, com indústrias que fornecem peças e equipamentos para indústrias da região e automotiva nacional; c) químico, com indústrias de plástico descartáveis e de embalagens, de tintas, vernizes e solventes para uso industrial e predial, e d) vestuário, com a produção, facção e comercialização de roupas de moda adulto e infantil (GOULARTI FILHO, 2004).

A coleta de dados ocorreu ao longo dos anos de 2012 e 2013 e totalizou em 192 questionários respondidos nos mais diversos segmentos econômicos. Os questionários foram coletados pelos colaboradores da pesquisa junto aos responsáveis pela gestão de tesouraria nas organizações. A pesquisa caracteriza-se como amostra intencional por acessibilidade, uma vez que gestores que responderam as informações aceitaram participar da pesquisa. O Quadro 4 expõe a estrutura do questionário utilizado.

Quadro 4- Estrutura do questionário

\begin{tabular}{|l|l|}
\hline \multicolumn{1}{|c|}{ Seções } & \multicolumn{1}{c|}{ Informações } \\
\hline $\begin{array}{l}\text { 1) Características das } \\
\text { organizações }\end{array}$ & Denominação social, setor de atuação, natureza jurídica e porte. \\
\hline 2) Atividades de Tesouraria & $\begin{array}{l}\text { Fluxo de caixa, controle de caixa, orçamento de caixa, planejamento } \\
\text { financeiro, entre outras. }\end{array}$ \\
\hline $\begin{array}{l}\text { 3) Modalidades de aplicações e } \\
\text { captações de recursos }\end{array}$ & $\begin{array}{l}\text { Tipos de investimentos, empréstimos e financiamentos utilizados no } \\
\text { mercado financeiro. }\end{array}$ \\
\hline $\begin{array}{l}\text { 4) Fontes de captações de } \\
\text { recursos }\end{array}$ & $\begin{array}{l}\text { Tipos de instituições financeiras que financiam bens ou recursos } \\
\text { financeiros para as organizações. }\end{array}$ \\
\hline
\end{tabular}

Fonte: Elaborado pelos autores.

Os dados foram tratados no software Microsoft Excel para a geração de tabelas e gráficos das características da gestão financeira das empresas da região.

\section{Apresentação e Análise dos Resultados}

Nesta seção apresentam-se os resultados da pesquisa realizada conforme os objetivos específicos estabelecidos, que são: (i) descrever as características das organizações; (ii) 
verificar aspectos administrativos de tesouraria; (iii) conhecer as modalidades de aplicações e de captações de recursos e (iv) verificar as fontes de captação de recursos.

\subsection{Características das organizações}

Nesta seção são apresentadas as características das organizações quanto à: natureza jurídica, setor de atuação e porte. As entidades foram classificadas de acordo com as seguintes naturezas jurídicas: Sociedade Anônima - S.A., Sociedade Ltda., Empresário Individual e Outras (caso não classificadas em nenhuma das categorias anteriores). A Tabela 1 mostra o resultado dessa classificação.

Tabela 1 - Natureza jurídica

\begin{tabular}{lccc}
\hline \multicolumn{1}{c|}{ Natureza Jurídica } & Quantidade & $\%$ \\
\hline S.A. & 11 & 5,73 \\
Ltda. & 149 & 77,60 \\
Empresário Individual & 16 & 8,33 \\
Outras & 16 & 8,33 \\
\hline \multicolumn{2}{c}{ Total } & 192 & 100,00 \\
\hline
\end{tabular}

Fonte: Dados da pesquisa

A maioria das empresas pesquisadas $(77,6 \%)$ é Sociedade Ltda., seguido das modalidades: Empresário Individual e Outros, com proporção de 8,33\% cada. O resultado mostra que os empreendedores procuram mais segurança no momento de montar um negócio, pois preferem compartilhar a gestão da empresa com sócios, proteger o patrimônio pessoal e utilizar os benefícios da legislação para as empresas de natureza Ltda., como por exemplo: custo de abertura inferior ao da sociedade anônima, estrutura administrativa mais simplificada e, principalmente, pode se beneficiar das vantagens do regime tributário SIMPLES Nacional (sistema tributário diferenciado, simplificado e favorecido para algumas atividades).

Das 192 organizações investigadas, a classificação econômica ficou do seguinte modo: 70atuam no comércio (36,46\%), 62 são de prestação de serviços $(32,29 \%)$ e 60 operam na indústria (31,25\%). Percebe-se uma distribuição equilibrada entre os setores econômicos da região. Isso mostra que a região permite a diversificação de empreendimentos para atender a demanda de diversos mercados consumidores.

A classificação de acordo com o porte resultou em: 116 empresas como micro e pequeno porte $(60,42 \%), 54$ empresas como médio porte $(28,13 \%)$ e 22 empresas como grande porte(11,46\%). Nota-se que na região a maior parcela das organizações é de micro e pequenas empresas, portanto possuem faturamento de até R\$ 3.600.000,00ao ano, conforme a Lei Complementar n. 139, de 10 de novembro de 2011.

\subsection{Aspectos de gestão de tesouraria}

A gestão de tesouraria é responsável pela movimentação de entradas e saídas de recursos das organizações. A Tabela 2 evidencia as práticas de gestão de tesouraria utilizadas pelas empresas.

Tabela 2 - Elementos de gestão de tesouraria

\begin{tabular}{c|l|c|c|c|c|c|c}
\hline Item & \multicolumn{1}{c}{ Questionário de avaliação de tesouraria } & Sim & $\%$ & Não & $\%$ & Total & $\%$ \\
\hline 1 & Há controle do Fluxo de Caixa? & 179 & 93,23 & 13 & 6,77 & 192 & 100,00 \\
2 & $\begin{array}{l}\text { Existem projeções de entradas e saídas de curto prazo? } \\
\text { (Orçamento de Caixa) }\end{array}$ & 147 & 76,56 & 45 & 23,44 & 192 & 100,00 \\
3 & $\begin{array}{l}\text { Existem projeções de entradas e saídas de longo prazo? } \\
\text { (Orçamento de Caixa) }\end{array}$ & 126 & 65,63 & 66 & 34,38 & 192 & 100,00
\end{tabular}




\begin{tabular}{llllllll}
4 & Há controle entre o Fluxo de Caixa Orçado e Realizado? & 124 & 64,58 & 68 & 35,42 & 192 & 100,00 \\
5 & $\begin{array}{l}\text { Há planejamento financeiro com políticas de } \\
\text { investimentos e de empréstimos/financiamentos? }\end{array}$ & 115 & 59,90 & 77 & 40,10 & 192 & 100,00 \\
\hline
\end{tabular}
Fonte: Dados da pesquisa.

Das 192 organizações investigadas, 179 realizam o controle de Fluxo de Caixa $(93,23 \%) ; 147$ fazem projeções de entradas e saídas de curto prazo $(76,56 \%), 126$ efetuam projeções de entradas e saídas de longo prazo (65,34\%), 124 realizam o controle entre o Fluxo de Caixa Orçado e Realizado (64,58\%) e em 115 ocorre o planejamento financeiro com definição de políticas de investimento, de empréstimos e de financiamentos $(59,90 \%)$.

Verifica-se que o uso do Fluxo de Caixa para controle da movimentação dos recursos é fundamental para a maioria das organizações (item 1). Tal resultado converge com a literatura que menciona que o Fluxo de Caixa é um dos instrumentos gerenciais mais eficazes para a gestão financeira das organizações, pois permite o controle, a coordenação e o planejamento dos recursos financeiros (ZDANOWICZ, 2004; HOJI, 2000; GITMAN, 2010; GROPPELLI, NIKBAKHT, 2010; LEMES JÚNIOR, RIGO, CHEROBIM, 2010).

Nos itens 2 e 3, constata-se que as projeções de orçamento de caixa tanto de curto quanto de longo prazo são utilizadas por uma parcela significativa das organizações. Entretanto, outra parcela de empresas, principalmente as micro e pequenas, não utiliza tal prática. Isso mostra que essas entidades têm deficiências de planejamento financeiro. Logo podem estar sujeitas a problemas financeiros não previstos pelos gestores. Esta realidade de certa forma prejudica a tomada de decisão de longo prazo e o estabelecimento de metas que visem ao crescimento do negócio.

Embora ainda não sejam alarmantes, os resultados referentes ao item 4 demonstram que $35,42 \%$ das empresas pesquisadas não têm controle sobre o fluxo de caixa orçado e realizado, o que pode acarretar em problemas de controle administrativo.

No item 5, percebe-se que uma parcela significativa de empresas $(40,10 \%)$ não realiza planejamento financeiro de investimentos e de empréstimos/financiamentos. Tal situação ocorre, principalmente, nas micro e pequenas empresas. Isso mostra que essas organizações têm debilidades na gestão financeira no que tange à definição de políticas de crescimento e de perpetuidade dos negócios, pois não planejam o futuro organizacional.

\subsection{Gestão de investimentos e de empréstimos/financiamentos}

As decisões de investimentos referem-se às sobras de recursos disponíveis para a aplicação no mercado financeiro. A Tabela 3 evidencia os tipos de investimentos utilizados pelas empresas da região.

Tabela 3 - Investimentos

\begin{tabular}{l|c|c|c|c|c|c}
\hline Tipos de Investimentos & Sim & $\%$ & Não & $\%$ & Total & $\%$ \\
\hline Caderneta de Poupança & 13 & 6,77 & 179 & 93,23 & 192 & 100,00 \\
Renda Fixa (CDB, RDB, Públicos) & 45 & 23,43 & 147 & 76,57 & 192 & 100,00 \\
Renda Variável (Ações) & 7 & 3,64 & 185 & 96,36 & 192 & 100,00 \\
Fundo de Investimentos & 19 & 9,89 & 173 & 90,11 & 192 & 100,00 \\
Outros Investimentos & 4 & 2,08 & 188 & 97,92 & 192 & 100,00 \\
\hline
\end{tabular}

Fonte: Dados da pesquisa.

Os resultados apontam que a maioria das empresas não aplica recursos no mercado financeiro. Para as organizações que aplicam, os recursos são destinados para investimentos em títulos de Renda Fixa. Essa aplicação tem rentabilidade conservadora e de rápido resgate em caso de necessidade. 
Os empréstimos são recursos em espécie captados para dar suporte às atividades operacionais. A Tabela 4 mostra os tipos utilizados pelas empresas.

Tabela 4 - Empréstimos

\begin{tabular}{lcc|c|c|c|c}
\hline \multicolumn{1}{c|}{ Tipos de Empréstimos } & Sim & $\%$ & Não & $\%$ & Total & $\%$ \\
\hline Cheque Especial - PJ & 20 & 10,41 & 172 & 89,59 & 192 & 100,00 \\
Desconto Duplicata/Nota Promissória & 34 & 17,70 & 158 & 82,29 & 192 & 100,00 \\
Capital de Giro & 50 & 26,04 & 142 & 73,96 & 192 & 100,00 \\
Empréstimo de Curto Prazo & 46 & 23,96 & 146 & 76,04 & 192 & 100,00 \\
Conta Garantida & 31 & 16,15 & 161 & 83,85 & 192 & 100,00 \\
Outros tipos de Empréstimos & 16 & 8,33 & 176 & 91,67 & 192 & 100,00 \\
\hline
\end{tabular}

Fonte: Dados da pesquisa.

Poucas empresas realizam captação de recursos. Das empresas pesquisadas e que possuem empréstimos, destacam-se as seguintes modalidades: Capital de Giro (26,04\%) e Empréstimos de Curto Prazo (23,95\%). Essas modalidades são operações financeiras de curto prazo que visam subsidiar as atividades operacionais cotidianas, como por exemplo: pagar fornecedores, impostos e salários, entre outros compromissos.

Em relação às operações de financiamentos de bens duráveis, os resultados são exibidos na Tabela 5 .

Tabela 5 - Financiamentos

\begin{tabular}{l|c|c|c|c|c|c}
\hline \multicolumn{1}{c|}{ Tipos de Financiamento } & Sim & $\%$ & Não & $\%$ & Total & $\%$ \\
\hline Financiamento/leasing de veículos & 59 & 30,73 & 133 & 69,27 & 192 & 100 \\
Financiamento/leasing de máquinas e equipamentos & 42 & 21,87 & 150 & 78,13 & 192 & 100 \\
Financiamento/leasing de instalações físicas & 10 & 5,21 & 182 & 94,79 & 192 & 100 \\
Outro tipo de financiamento/leasing & 1 & 0,05 & 191 & 99,95 & 192 & 100 \\
\hline
\end{tabular}

Fonte: Dados da pesquisa.

Muitas empresas financiam veículos (30,79\%), máquinas e equipamentos $(21,87 \%)$ para as atividades de produção e prestação de serviços. Observa-se que esses bens são fundamentais para o funcionamento das organizações.

\subsection{Fontes de captação}

O mercado financeiro proporciona diversas instituições financeiras para a captação de recursos, de acordo com as necessidades de cada organização. A Tabela 6 apresenta as fontes de captação utilizadas.

Tabela 6 - Fontes de captação

\begin{tabular}{l|c|c|c|c|c|c}
\hline \multicolumn{1}{c|}{ Fontes de Captação de Recursos } & Sim & $\%$ & Não & $\%$ & Total & $\%$ \\
\hline Empresas de Factoring & 14 & 7,29 & 178 & 92,71 & 192 & 100,00 \\
Bancos de Investimentos & 7 & 3,65 & 185 & 96,35 & 192 & 100,00 \\
Bancos Múltiplos/Comerciais & 133 & 69,27 & 59 & 30,73 & 192 & 100,00 \\
Bancos de Desenvolvimento & 58 & 30,21 & 134 & 69,79 & 192 & 100,00 \\
Cooperativas de Crédito & 30 & 15,62 & 162 & 84,38 & 192 & 100,00 \\
Sociedades de Arrendamento Mercantil & 22 & 11,46 & 170 & 88,54 & 192 & 100,00 \\
Sociedades de Crédito & 8 & 4,17 & 184 & 95,83 & 192 & 100,00 \\
Outra fonte & 12 & 6,25 & 180 & 93,75 & 192 & 100,00 \\
\hline
\end{tabular}

Fonte: Dados da pesquisa. 
As principais fontes de recursos para as empresas são os Bancos Múltiplos/Comerciais $(69,27 \%)$ e Bancos de Desenvolvimento (30,21\%). Os Bancos Múltiplos/Comerciais são instituições que oferecem uma série de modalidade de empréstimos e financiamentos, tanto de curto como de longo prazo. Essas instituições estão mais próximas das entidades, pois recebem aplicações e prestam serviços bancários de cobrança e seguros, entre outros. Por isso, os Múltiplos/Comerciais prevalecem em relação às demais instituições.

Os Bancos de Desenvolvimento, por sua vez, são responsáveis pelo financiamento de bens duráveis, logo seu papel é proporcionar recursos de longo prazo para que as organizações consigam investir no aumento da capacidade produtiva, no atendimento de clientes e na criação de novos produtos e serviços.

\section{Considerações Finais}

A administração financeira é responsável por maximizar o valor do negócio por meio de processos gerenciais que permitam o controle dos investimentos realizados nas organizações. Dentre os processos gerenciais financeiros destaca-se a tesouraria, que é responsável em controlar as entradas e saídas de recursos financeiros, além de orientar as ações gerenciais em relação ao planejamento financeiro.

Nesse contexto, o presente estudo teve por objetivo investigar as características de gestão de tesouraria nas organizações da região da AMREC, de Santa Catarina. Os resultados mostraram que das 192 empresas investigadas a maioria: a) é de natureza jurídica Ltda. $(77,6 \%)$; b) atua no comércio $(36,46 \%)$ e na prestação de serviços $(32,29 \%)$; c) é de micro e pequeno porte $(60,42 \%)$; d) possui práticas adequadas de gestão de tesouraria de curto prazo; e) tem poucas aplicações e empréstimos no mercado financeiro; f) realiza financiamentos para veículos, máquinas e equipamento e g) capta recursos em Bancos Múltiplos/Comerciais $(69,27 \%)$ e Bancos de Desenvolvimento (30,21\%).

Esses resultados evidenciam que as organizações pesquisadas possuem uma situação organizacional de gestão adequada de tesouraria de curto prazo. Entretanto, nas atividades de tesouraria de longo prazo muitas empresas de micro e pequeno porte não realizam controles de orçado/realizado e de planejamento financeiro com políticas de investimentos, empréstimos e financiamentos.

Tal situação representa uma fragilidade importante de gestão financeira, pois evidencia que algumas organizações não possuem visão de longo prazo para assegurar a continuidade do negócio. Esse resultado converge com as pesquisas dos autores Neves; Pessoa (2006); SEBRAE-SP (2008) e Santos; Ferreira e Faria (2009), que ressaltam a importância do planejamento para a longevidade organizacional.

Cabe salientar que a prática do planejamento financeiro é um dos fatores essenciais para a sobrevivência das organizações. Logo, os gestores devem ficar atentos às necessidades organizacionais para evitar a falta de liquidez nas operações e a descontinuidade dos negócios.

Por fim, como sugestão para futuras pesquisas, recomenda-se: investigar os motivos de uso e/ou de não uso do planejamento financeiro, verificar os tipos de instrumentos financeiros utilizados para a gestão financeira e entrevistar os responsáveis da área financeira para compreender o modo de utilização das informações financeiras para a tomada de decisão.

\section{Referências}

ASSAF NETO, A. Mercado financeiro. 7. ed. São Paulo: Atlas, 2007. 
ASSOCIAÇÃO DOS MUNICÍPIOS DA REGIÃO CARBONÍFERA - AMREC. Criciúma, 2012. Disponível em: <http://www.amrec.com.br> Acessado em 12 mar. 2014.

BRASIL. Lei Complementar n. 139, de 10 de novembro de 2011. Alteram dispositivos da Lei Complementar n. 123, de 14 de dezembro de 2006, e dá outras providências. Disponível em: $<$ http://www.planalto.gov.br/ccivil_03/Leis/LCP/Lcp139.htm\#art5>. Acessado em 02 fev. 2014.

FARIAS, E. E. V. Matemática financeira aplicada: aplicada às operações do mercado financeiro, com utilização da calculadora HP12C. Santa Maria: Ed. do Autor, 2002.

GITMAN, L. J. Princípios de administração financeira. 12. ed. São Paulo: Pearson Addison Wesley, 2010.

GOULARTI FILHO, A. Caderno de informações socioeconômicas da AMREC: séries históricas. Criciúma, SC: UNESC, 2004.

GROPPELLI, A. A.; NIKBAKHT, E. Administração financeira. 3. ed. São Paulo: Saraiva, 2010 .

HOJI, M. Administração financeira: uma abordagem prática - matemática financeira aplicada, estratégia financeiras, análise, planejamento e controle financeiro. 2.ed. São Paulo: Atlas, 2000 .

LEMES JÚNIOR, A. B.; RIGO, C. M.; CHEROBIM, A. P. M. S. Administração financeira: princípios, fundamentos e práticas brasileiras, aplicações e casos nacionais. 3. ed. Rio de Janeiro: Campus, 2010.

LIMA, I. S.; LIMA, G. A. S. F.; PIMENTEL, R. C. Curso de mercado financeiro. 2. ed. São Paulo: Atlas, 2012.

MARTINS JUNIOR, J. Como escrever trabalhos de conclusão de curso: instruções para planejar e montar, desenvolver, concluir, redigir e apresentar trabalhos monográficos e artigos. Petrópolis: Vozes, 2008.

NEVES, J.A.D.; PESSOA, R.W.A.P. Causas da mortalidade de micro e pequenas empresas: o caso das lojas de um Shopping Center. Revista Organizações em Contexto, v. 2, n.4, p. 165 $195,2006$.

PACHECO, M. M.; OLIVEIRA, G. A.Mercado financeiro. São Paulo: Fundamento, 2005.

PINHEIRO, J. M. Da iniciação científica ao TCC: uma abordagem para os cursos de tecnologia. Rio de Janeiro: Ciência Moderna, 2010.

RICHARDSON, R. J.Pesquisa social: métodos e técnicas. 3. ed. rev. e ampl. São Paulo: Atlas, 1999.

ROSS, S. A.; JAFFE, J.

F.;WESTERFIELD,R. Administraçãofinanceira: corporatefinance. São Paulo: Atlas, 2002. 
SANTOS, E. O. Administração financeira da pequena e média empresa. São Paulo: Atlas, 2001.

SANTOS, L. M.; FERREIRA, M. A. M.; FARIA, E. R.Gestão financeira de curto prazo: características, instrumentos e práticas adotadas por micro e pequenas empresas. Revista de Administração da UNIMEP, v. 7, n.3, 2009.

SERVIÇO DE APOIO ÀS MICRO E PEQUENAS EMPRESAS - SÃO PAULO (SEBRAESP). 10 anos de monitoramento da sobrevivência e mortalidade de empresas. São Paulo: SEBRAE-SP, 2008.

SILVA, J. P. Análise financeira das empresas. 8. ed. São Paulo: Atlas, 2007. . Gestão e análise de risco de crédito. 6. ed. São Paulo: Atlas, 2008.

WERNKE, R. Gestão financeira:ênfase em aplicações e casos nacionais. Rio de Janeiro: Saraiva, 2008.

ZDANOWICZ, J. E. Fluxo de caixa: uma decisão de planejamento e controle financeiro. 10. ed. Porto Alegre: Sagra Luzzatto, 2004. 